\title{
(C) OPEN ACCESS \\ Advancing prevention of sexually transmitted infections through point-of-care testing: target product profiles and landscape analysis
}

\author{
Igor Toskin, ${ }^{1}$ Maurine Murtagh, ${ }^{2}$ Rosanna W Peeling, ${ }^{3}$ Karel Blondeel, ${ }^{1,4}$ \\ Joanna Cordero, ${ }^{1}$ James Kiarie ${ }^{1}$
}

'Department of Reproductive Health and Research, World Health Organization (WHO) Geneva, Switzerland

${ }^{2}$ The Murtagh Group, Limited Liability Company (LLC). Woodside, USA ${ }^{3}$ London School of Hygiene and Tropical Medicine (LSHTM) London, UK

${ }^{4}$ Faculty of Medicine and Health Sciences, Ghent University, Ghent, Belgium

\section{Correspondence to} Dr Igor Toskin, Department of Reproductive Health and Research, World Health Organization (WHO), Geneva, Switzerland; toskini@who.int

Received 9 March 2017 Revised 16 October 2017 Accepted 27 October 2017

\section{(1) crossark}

To cite: Toskin I, Murtagh M, Peeling RW, et al. Sex Transm Infect 2017:93:S69-S80.

\section{ABSTRACT}

Objectives Advancing the field of point-of-care testing (POCT) for STIs can rapidly and substantially improve STI control and prevention by providing targeted, essential STI services (case detection and screening). POCT enables definitive diagnosis and appropriate treatment in a single visit and home and community-based testing.

Methods Since 2014, the WHO Department of Reproductive Health and Research, in collaboration with technical partners, has completed four landscape analyses of promising diagnostics for use at or near the point of patient care to detect syphilis, Neisseria gonorrhoeae, Chlamydia trachomatis, Trichomonas vaginalis and the human papillomavirus. The analyses comprised a literature review and interviews. Two International Technical Consultations on STI POCTs (2014 and 2015) resulted in the development of target product profiles (TPP). Experts in STI microbiology, laboratory diagnostics, clinical management, public health and epidemiology participated in the consultations with representation from all WHO regions.

Results The landscape analysis identified diagnostic tests that are either available on the market, to be released in the near future or in the pipeline. The TPPs specify 28 analytical and operational characteristics of POCTs for use in different populations for surveillance, screening and case management. None of the tests that were identified in the landscape analysis met all of the targets of the TPPs.

Conclusion More efforts of the global health community are needed to accelerate access to affordable quality-assured STI POCTs, particularly in low- and middle-income countries, by supporting the development of new diagnostic platforms as well as strengthening the validation and implementation of existing diagnostics according to internationally endorsed standards and the best available evidence.

\section{INTRODUCTION}

STIs, including HIV, continue to be a significant global public health issue. The WHO estimated 357 million new cases of four curable STIs caused by: Treponema pallidum (syphilis) (6 million), Chlamydia trachomatis (CT) (131 million), Neisseria gonorrhoeae (NG) (78 million) and Trichomonas vaginalis (TV) (143 million). ${ }^{1}$ In addition, more than 290 million women are infected with the human papillomavirus (HPV). ${ }^{2}$

Curable STIs continue to be a high burden on global health even though, in most cases, they can be treated with a single-dose antibiotic cure. WHO has estimated that about 1.86 million cases of syphilis occur worldwide among pregnant women each year, many of whom are either untreated or inadequately treated. ${ }^{3}$ Untreated maternal syphilis is believed to cause more than 500000 perinatal deaths (ie, deaths that occur from 22 weeks' gestation through the first seven days of life) each year. ${ }^{4 i}$ In addition, about 220000 children became newly infected with HIV in 2014, making up more than $10 \%$ of the total number of new HIV infections. ${ }^{5}$

Reliable, affordable diagnostic tests are key components of effective STI control and prevention, their absence is an obstacle to reducing the STI burden. With some exceptions, the existing diagnostics for these STIs are laboratory-based platforms, which typically require a robust laboratory infrastructure and well-trained laboratory technicians. ${ }^{6}$ In addition, turnaround time is often long, requiring patients to return for test results on a subsequent clinic visit. This often leads to significant loss to patient follow-up. Therefore, while these laboratory-based diagnostics are effective, they may not always be suitable for use in resource-limited settings where diagnostic access to and delivery of appropriate diagnostics can be challenging. This is important, since $80 \%-90 \%$ of the global STI burden occurs in the developing world. ${ }^{7}$

One of the major barriers to advancing the field of diagnostic tests for STIs is the absence of reliable, low-cost, point-of-care tests (POCTs). These tests offer immediate results allowing patients to receive diagnosis and treatment in one, and possibly the only, visit. POCTs are often equipped with readers that enable data transmission, offering the potential for improved STI surveillance and facilitating all aspects of effective STI control. ${ }^{8}$

The WHO Global Health Sector Strategy on Sexually Transmitted Infections, 2016-2021, highlights POCT as one of the innovations to accelerate universal health coverage, emphasising discovery, development and rapid uptake, complemented with research to optimise implementation and impact of these STI POCTs. ${ }^{9}$

${ }^{\mathrm{i}}$ This compares to annual death rates for other important infections in pregnancy, such as HIV, which is estimated to cause between 250000 and 290000 perinatal deaths worldwide, and malaria in pregnancy, which is estimated to cause about 200000 perinatal deaths. 
In 2006, WHO introduced the ASSURED criteria for POCTs for use at the level 1 health centre: Affordable, Sensitive, Specific, User-friendly, Rapid and robust, Equipment-free and Deliverable to end-users. Although notable progress has been made in developing diagnostic tests for syphilis, chlamydial and gonococcal infections, and trichomoniasis, ${ }^{10-14}$ there are still no tests available that comply with all these criteria.

To accelerate advancements in the field of STI POCT, WHO facilitated landscape analyses of potential point-of-care diagnostic technologies for dual HIV/syphilis tests, CT, NG, TV and HPV, available and in the pipeline. It concurrently organised expert meetings to conceive target product profiles (TPP) for POCTs for these infections. This article describes the processes and results of these two initiatives and considers whether the current diagnostic pipeline is adequate following the TPPs.

\section{METHODOLOGIES}

The landscape analysis was conducted through both primary and secondary sources. The secondary sources included (1) published literature; (2) published and unpublished reports; (3) WHO policies; and (4) websites of diagnostic manufacturers and developers. For the literature review, the following databases were searched-PubMed, Scopus and Web of Science using the terms 'test', 'testing', 'performance' and 'diagnosis' together with 'sexually transmitted infection', 'human immunodeficiency virus', 'HIV', 'syphilis', 'Chlamydia trachomatis', 'Neisseria gonorrhoeae', 'Trichomonas vaginalis', 'human papillomavirus' and 'HPV'. Additional web sources, including Google, were also searched to identify diagnostic platforms and tests for STIs. Additional reviews of published literature informed on the performance and operational characteristics of these tests and indicated when independent performance data were not available. To deepen the landscape analysis, primary sources were also used. Informal telephone interviews were conducted with representatives from the companies/developers of interest. Questions, tailored to the individual company/developer, were generally of a technical nature about the diagnostic platform/ test(s), and in the case of platforms in the pipeline, they also included inquiries about the development path for the platform/test(s) and expected commercial launch. Summaries of each platform/test were written and reviewed for accuracy with representatives from the company/developer associated with the platform/test. The first landscape analysis was conducted in early 2014 to inform the first WHO Technical Consultation on STI POCT in May 2014. ${ }^{15}$ The landscape was updated in 2015 prior to the second WHO Technical Consultation on STI POCT. The third update was completed in December 2016. The analysis was conducted through an iterative process as part of efforts to address the ever-evolving and dispersed nature of the field of POCT.

The development of the TPPs was initiated through reviewing the pooled performance data from systematic reviews commissioned by WHO, published predictive models to inform test performance, and the lower limits of detection of technologies identified in the landscape analyses and then further developed through a series of face-to-face and online consultations with an international expert group (IEG) using an adapted Delphi methodology. The initial list of 28 parameters for the TPPs was adapted from the TPP for dual HIV/syphilis tests commissioned in 2013 by UNITAID. ${ }^{16}$ The intended use and target populations, sexually active with a focus on STI clinic attendees, pregnant women, men who have sex with men (MSM) and sex workers (SW), were selected according to the current international guidelines for STI surveillance, case management and screening programmes for syphilis, NG, CT, TV and HPV. ${ }^{17-23}$ TPP parameters were expressed as minimal and optimal recommendations, in order to reflect the range of needs of healthcare providers and patient populations within the intended use of the tests using a public health approach.

The IEG consisted of 32 internationally recognised STI experts, including clinicians, microbiologists, professionals in the field of laboratory medicine, public health, social science, and diagnostic technology and development, from all WHO regions. The IEG also comprised representatives from WHO, UNITAID, and the Foundation for Innovative New Diagnostics (FIND). All experts were assessed for conflicts of interest, none were found.

At the first meeting in May 2014, the group assessed and endorsed the list of TPP parameters. Small group work resulted in the first draft TPPs for each of the POCTs to detect STIs. The draft TPPs were then discussed with all the participants and reconciled according to the feedback, taking into consideration agreements and disagreements between the small groups and the plenary. During both the small group and plenary sessions, the first STI diagnostic landscape was used as a reference by participants, allowing them to compare proposed minimal and optimal TPP characteristics with those of existing STI tests. Because of the oncogenicity of the pathogen, the proposed TPPs for POCTs to detect HPV were reviewed by professional associations. ${ }^{\text {ii }}$ The refined TPPs were then presented and reviewed at the second technical consultation in July 2015. All comments and points discussed during the second expert group meeting were documented and reflected in the revised TPPs as a consensus-based agreement among all stakeholders. The IEG assessed and endorsed the TPP parameters through several rounds of online consultations. The final TPPs were consolidated and published on the WHO website, http://www.who.int/reproductivehealth/ topics/rtis/pocts/en/.

\section{RESULTS \\ Syphilis}

Landscape

A range of POCTs for syphilis has been developed. These tests are antibody tests that detect treponemal (TP) antibodies. Among these are tests from Alere (Alere Determine), Alere/Standard Diagnostics (SD Syphilis 3.0), The Tulip Group/Qualpro (Syphicheck-WB) and Omega Diagnostics (Visitect Syphilis), OnSite Syphilis Ab Combo Rapid Test (CTK Biotech), Syphilis Health Check (Trinity Biotech) and Uni-Gold Syphilis Treponemal (Trinity Biotech). Of these tests, all but Syphilis Health Check are CE-IVD marked; Syphilis Health Check is approved by the US Food and Drug Administration (FDA) and CLIA waived in the USA. These tests are summarised in table 1.

Historically, there have been concerns about the performance of TP POCTs. However, a recent meta-analysis on the performance of Alere Determine Syphilis TP, SD Syphilis 3.0, Syphicheck WB and Visitect Syphilis demonstrated sensitivity and specificity estimates comparable to laboratory-based tests. ${ }^{17}$ Test performance, from which the authors conclude that the tests are useful in resource-constrained settings where access to laboratory testing for syphilis is limited, is summarised in table 2 .

There are no peer-reviewed evaluations of the Uni-Gold Treponemal test, but independent reviews demonstrated good

${ }^{i i}$ American Cancer Society, Basic Health International, Global Coalition Against Cervical Cancer (GC3), Preventive Oncology International. 
Table 1 Selected POCTs for detection of syphilis: summary of selected operational characteristics from product inserts

\begin{tabular}{|c|c|c|c|c|}
\hline $\begin{array}{l}\text { Test } \\
\text { (manufacturer) }\end{array}$ & Specimen & $\begin{array}{l}\text { Volume of whole blood or } \\
\text { other specimen }\end{array}$ & Time to result (min) & Test type \\
\hline $\begin{array}{l}\text { Alere Determine } \\
\text { Syphilis TP } \\
\text { Alere (USA) }\end{array}$ & Whole blood (fingerstick), plasma or serum & $50 \mu \mathrm{L}$ & $15 \mathrm{~min}$ (up to 24 hours) & Lateral flow strip \\
\hline $\begin{array}{l}\text { SD Syphilis } 3.0 \\
\text { Alere/SD Bioline (South Korea) }\end{array}$ & $\begin{array}{l}\text { Whole blood (venous or fingerstick), plasma } \\
\text { or serum }\end{array}$ & $\begin{array}{l}20 \mu \mathrm{L} \text { (whole blood) } \\
10 \mu \mathrm{L} \text { (plasma or serum) }\end{array}$ & $5-20 \mathrm{~min}$ & Cassette enclosed test card \\
\hline $\begin{array}{l}\text { Syphicheck-WB } \\
\text { The Tulip Group/Qualpro (India) }\end{array}$ & $\begin{array}{l}\text { Whole blood (venous or fingerstick), plasma } \\
\text { or serum }\end{array}$ & $25 \mu \mathrm{L}$ & $15 \mathrm{~min}$ & Cassette enclosed test card \\
\hline $\begin{array}{l}\text { Visitect Syphilis } \\
\text { Omega Diagnostics (UK) }\end{array}$ & $\begin{array}{l}\text { Whole blood (venous or fingerstick), plasma } \\
\text { or serum }\end{array}$ & $50 \mu \mathrm{L}$ & $30 \mathrm{~min}$ & Cassette enclosed test card \\
\hline $\begin{array}{l}\text { OnSite Syphilis Ab Combo Rapid Test } \\
\text { CTK Biotech (USA) }\end{array}$ & Whole blood (venous or fingerstick) & 1 drop & $15 \mathrm{~min}$ & Cassette enclosed test card \\
\hline $\begin{array}{l}\text { Syphilis Health Check } \\
\text { Trinity Biotech (Ireland) }\end{array}$ & Whole blood (fingerstick), plasma or serum & 2 drops & $10 \min$ & Cassette enclosed test card \\
\hline $\begin{array}{l}\text { Uni-Gold Syphilis Treponemal } \\
\text { Trinity Biotech (Ireland) }\end{array}$ & $\begin{array}{l}\text { Whole blood (venous or fingerstick), plasma } \\
\text { or serum }\end{array}$ & $\sim 60 \mu$ & $\sim 15 \mathrm{~min}$ & Cassette enclosed test card \\
\hline
\end{tabular}

POCTs, point-of-care tests.

sensitivity and specificity for both the OnSite Syphilis Ab Combo Rapid Test and the Syphilis Health Check tests. ${ }^{18} 19$

It should be noted that the TP POCTs described above cannot be used to distinguish between active and past treated infections due to the persistence of TP antibodies. In resource-limited settings, where many people do not have access to laboratory-based non-TP tests for confirmation of active syphilis, pregnant women who are found to be seropositive with a TP POCT are treated for syphilis in order to prevent any possibility of transmission of the infection.

This highlights the need for a combination TP/non-TP test that can be used to diagnose syphilis at the point of care (POC). The DPP Syphilis Screen \& Confirm Assay (Chembio Diagnostic Systems) is such a test. It requires a sample size of only $10 \mu \mathrm{L}$ of whole blood (fingerstick or venepuncture), and tests can be stored at room temperature $\left(2^{\circ} \mathrm{C}-30^{\circ} \mathrm{C}\right)$. The turnaround time of the test is $15-20 \mathrm{~min}$. The test has been shown to be highly sensitive and specific, and also useful for the serological diagnosis of syphilis in primary healthcare clinics or resourcepoor settings. ${ }^{2021}$ Performance of the assay from three evaluations is summarised in table 3 . Although conducted using varying methodologies and samples, each of the studies concluded that the DPP Screen \& Confirm Assay could be useful for diagnosing syphilis in primary healthcare settings in resource-limited settings.

In a laboratory-based evaluation using banked serum samples conducted by Castro et al the DPP TP and non-TP lines were compared with the Treponema pallidum particle agglutination (TPPA) assay and a quantitative rapid plasma regain (RPR) test, respectively. ${ }^{20}$ Yin et al conducted a multicentre field evaluation in China. ${ }^{21}$ Three kinds of specimens (whole blood, finger prick blood and blood plasma) were used; reference standards were the TPPA assay for the TP test and the toluidine red unheated serum test for the non-TP test. Lastly, the study by Causer $e t$ al was again laboratory-based and used serum samples. It compared the TP and non-TP test lines with immunoassays

Table 2 Meta -analysis data on performance of select TP POCTs for syphilis

\begin{tabular}{llll}
\hline POCT & Sample & Parameters & Assuming imperfect reference standards $(\mathbf{9 5} \%$ Crl)* \\
\hline Alere Determine & Serum & Sensitivity & $90.04 \%(80.45,95.21)$ \\
& & Specificity & $94.15 \%(89.26,97.66)$ \\
& Whole blood & Sensitivity & $86.32 \%(77.26,91.70)$ \\
SD Syphilis 3.0 & Serum & Specificity & $95.85 \%(92.42,97.74)$ \\
& & Sensitivity & $87.06 \%(75.67,94.50)$ \\
& Whole blood & Specificity & $95.85 \%(89.89,99.53)$ \\
& & Sensitivity & $84.50 \%(78.81,92.61)$ \\
Syphicheck-WB & Serum & Specificity & $97.95 \%(92.54,99.33)$ \\
& & Sensitivity & $74.48 \%(56.85,88.44)$ \\
& Whole blood & Specificity & $99.14 \%(96.37,100.0)$ \\
& & Sensitivity & $74.47 \%(63.94,82.13)$ \\
Visitect Syphilis & Specificity & $99.58 \%(98.91,99.96)$ \\
& Serum & Sensitivity & $85.13 \%(72.83,92.57)$ \\
& \multirow{3}{*}{ Whole blood } & Specificity & $96.45 \%(91.92,99.29)$ \\
& & Sensitivity & $74.26 \%(53.62,83.68)$ \\
& & Specificity & $99.43 \%,(98.22,99.98)$ \\
\hline
\end{tabular}

Adapted from Jafari et al. ${ }^{17}$

${ }^{*}$ Adjustments were made for imperfect reference standards using the Bayesian hierarchical summary receiver operating characteristic curve method. The results are point estimates of sensitivity and specificity for each test, using serum and whole blood, around a 95\% credible interval (as opposed to a $\mathrm{Cl}$ ).

$\mathrm{Crl}$, credible interval; NA, not available; POCT, point-of-care testing; TP, treponemal. 
Table 3 Performance of DPP Syphilis Screen \& Confirm Assay (Chembio Diagnostics Systems)

\begin{tabular}{|c|c|c|c|c|}
\hline Study & Sample & $\begin{array}{l}\text { Parameters \% } \\
(95 \% \mathrm{Cl})\end{array}$ & DPP Treponemal line & DPP Non-treponemal line \\
\hline \multirow[t]{2}{*}{ Castro et $\mathrm{al}^{20}$} & \multirow{2}{*}{$\begin{array}{l}\text { Banked serum } \\
\text { samples }\end{array}$} & Sensitivity & 96.5 (NA) & 98.4 (NA) \\
\hline & & Specificity & 95.5 (NA) & 98.6 (NA) \\
\hline \multirow[t]{6}{*}{ Yin et $a l^{21}$} & \multirow[t]{2}{*}{ Whole blood $(n=1323)$} & Sensitivity & $96.7(95.1-97.9)$ & $87.2(84.0-89.9)$ \\
\hline & & Specificity & $99.3(98.3-99.7)$ & $94.4(92.6-95.8)$ \\
\hline & \multirow[t]{2}{*}{ Finger prick blood $(n=488)$} & Sensitivity & $96.4(93.5-98.0)$ & $85.5(82.4-89.4)$ \\
\hline & & Specificity & $96.4(93.5-98.0)$ & $96.1(92.9-97.9)$ \\
\hline & \multirow[t]{2}{*}{ Blood plasma $(n=1323)$} & Sensitivity & $94.6(92.5-96.1)$ & $88.4(85.3-90.9)$ \\
\hline & & Specificity & $99.6(98.7-99.9)$ & $95.0(93.3-96.3)$ \\
\hline \multirow[t]{2}{*}{ Causer et $\mathrm{al}^{22}$} & \multirow[t]{2}{*}{ Serum $(n=1005)$} & Sensitivity & $89.8 \%(87.3-91.9)$ & $94.2(91.8-96.0)$ \\
\hline & & Specificity & $99.3 \%(97.0-99.9)$ & $62.2(57.5-66.6)$ \\
\hline
\end{tabular}

NA, not applicable.

and RPR as reference standards, respectively. ${ }^{22}$ Results of the studies are summarised in table 3.

\section{Target product profile}

The IEG agreed that the main goals of POCTs for syphilis is to detect T. pallidum, TP antibodies and non-TP antibodies. The agreed intended use was surveillance and case management among the sexually active population, including key populations (MSM, SW and STI clinic/service attendees), as well as screening of pregnant women and key populations. The results of the tests are expected to be quantitative (clear reactive, non-reactive or invalid) with minimal instructions for interpretation. A finger prick capillary blood, maximum $50 \mu \mathrm{L}$ with no more than one operator step as a minimal and $20 \mu \mathrm{L}$ integrated specimen preparation as optimal specimen characteristic, was agreed by the experts (table 4).

With regard to the clinical sensitivity of the TP component, a level of $>80 \%$ as minimally acceptable and a level of $>90 \%$ as optimal were endorsed by the IEG. Regarding the clinical specificity, the endorsed levels were $>90 \%$ and $>95 \%$, respectively. For the non-TP component, the agreed minimal level of clinical sensitivity were $>95 \%$ of high titre ( 1 in 8 ) and $>99 \%$ of high titre ( 1 in 8 ) as optimal level, the endorsed levels of clinical specificity were $>80 \%$ (minimal) and $>95 \%$ (optimal), respectively.

One of the critical characteristics of a POCT is the time to result, which is the time between sample collection and processing and getting the result. The IEG agreed that the minimal acceptable time to result for an ideal POCT for syphilis is up to $60 \mathrm{~min}$, and the optimal turnaround time should be $30 \mathrm{~min}$ or shorter. This recommendation is based on the currently available diagnostic technology, which is primarily lateral flow chromatography, as well as clinical practice with regard to syphilis case management and screening programmes, including in rural and remote areas with limited or no access to laboratory-based diagnostics. It was also agreed by the IEG that the POC diagnostic platform should have connectivity capability as a minimal TPP characteristic in order to support surveillance and monitoring activities within the syphilis control programmes. ${ }^{8}$ The IEG has also recommended the minimal acceptable target price per test as $<$ US $\$ 3$ (excluding the cost of a device or reader) and $<$ US\$1.5 as the optimal target price per test. The target prices were recommended according to the analysis of the current market as well as the WHO procurement mechanisms established for some diagnostic tests to detect syphilis.

\section{C. trachomatis, N. gonorrhoeae}

\section{Landscape}

The current POCTs for both CT and NG are immunoassays to detect antigen. ${ }^{23-25}$ Systematic reviews of their performance showed pooled sensitivities of less than 50\% for vaginal swabs compared with NAATs as reference standards. ${ }^{26} 27$ Improved assays are required, especially for women, for whom the syndromic approach to managing vaginal discharge is inadequate. ${ }^{28}$

There is currently one NAAT-based platform, the GeneXpert system manufactured by Cepheid, that is available for near-patient diagnosis of CT, NG and CT/NG combined. The GeneXpert is a fully automated and integrated, polyvalent system for PCR-based NAAT that allows random access so that assays for detection of different pathogens can be performed at the same time. The assay may be used on the following specimens from both asymptomatic and symptomatic patients: female and male urine, endocervical swabs collected in a clinical setting, including patient-collected vaginal swabs.

The GeneXpert system integrates and automates sample preparation, amplification and detection in a single-use, self-contained cartridge. The performance of the Xpert CT/NG assay has been evaluated and found to be very good relative to established laboratory-based assays. ${ }^{29-31}$

\section{CT, NG and CT/NG platforms/assays in the pipeline}

The main characteristics of POCTs and near-to-patient diagnostic platforms in the pipeline are presented in table 5 .

\section{Target product profile}

With respect to POCTs to detect NG and CT, the IEG discussed the main performance and operational characteristics of combined and mono-POCTs. Table 6 and 7 present the agreed minimal and optimal characteristics. The intended use of desired POCTs for both infections is the same as for syphilis, that is, surveillance and case management of NG and CT in sexually active populations as well as screening for asymptomatic infections in key populations, particularly MSM and SW at primary healthcare services or outreach, defined by the group as primary healthcare settings. The tests are expected to provide clear qualitative positive, negative or invalid results with minimal instructions by using vaginal swabs in women and urine in men as a minimally accepted specimen and urine in both men and women as well as vaginal self-collected specimen in women, and pharyngeal and rectal swabs, particularly for MSM. In order to address 
Table 4 TPP_combined TP and non-TP POCT for syphilis

\begin{tabular}{|c|c|c|c|c|}
\hline Goal of test & & \multicolumn{3}{|c|}{ To detect TP-specific antibodies and non-TP-specific antibodies } \\
\hline Intended use and target patient* & & \multicolumn{3}{|c|}{$\begin{array}{l}\text { Surveillance/case management: sexually active population, including key populations (eg, MSM, SW, STI clinic/service } \\
\text { attendees) } \\
\text { Screening: pregnant women, key populations }\end{array}$} \\
\hline Target use setting & & \multicolumn{3}{|c|}{ To detect TP-specific antibodies and non-TP-specific antibodies } \\
\hline Results & & \multicolumn{3}{|c|}{ Clear reactive, non-reactive or invalid result with minimal instructions for interpretation } \\
\hline Equipment & & \multicolumn{3}{|c|}{$\begin{array}{l}\text { Single-use diagnostic test preferred, reader optional (small, portable, tabletop or handheld, no electricity/power supply } \\
\text { required) }\end{array}$} \\
\hline Target use(s) & & TP component & \multicolumn{2}{|c|}{ Non-TP component } \\
\hline Reference technology & & TPPA & \multicolumn{2}{|l|}{ RPR } \\
\hline Performance & Minimal & Optimal & Minimal & Optimal \\
\hline Clinical sensitivity ${ }^{+}$ & $>80 \%$ & $>90 \%$ & $>95 \%$ of high titre $(1: 8)$ specimens & $>99 \%$ of high titre $(1: 8)$ specimens \\
\hline Clinical specificity & $>90 \%$ & $>95 \%$ & $>80 \%$ & $>95 \%$ \\
\hline Quantitation $\neq$ & \multicolumn{4}{|c|}{ Not applicable } \\
\hline
\end{tabular}

Key minimal and optimal operational characteristics for combined TP and non-TP POCT for syphilis

\begin{tabular}{|c|c|c|}
\hline & Minimal & Optimal \\
\hline Specimen & $\begin{array}{l}\text { Finger prick capillary blood (maximum } \\
50 \mu \mathrm{L} \text { ) }\end{array}$ & Finger prick capillary blood (maximum $20 \mu \mathrm{L}$ ) \\
\hline $\begin{array}{l}\text { Steps performed by healthcare worker between } \\
\text { specimen preparation and result }\end{array}$ & $\begin{array}{l}\text { No more than three operator steps } \\
\text { that are not timed nor labour intensive }\end{array}$ & $\begin{array}{l}\text { Maximum one operator step (none of which has a timed interval), excluding waste } \\
\text { disposal }\end{array}$ \\
\hline Training required & $<90$ min & $30 \mathrm{~min}$ \\
\hline Time to result & $=60 \mathrm{~min}$ & $=30 \mathrm{~min}$ \\
\hline Connectivity: device/reader & $\begin{array}{l}\text { If combined with a reader, reader has } \\
\text { integrated GPS module. }\end{array}$ & $\begin{array}{l}\text { If combined with a reader, internally integrated GPS/GPRS module and conformity } \\
\text { with } \mathrm{HL}-7 \text { messaging standards }\end{array}$ \\
\hline Data export (for quality assurance): device/reader & $\begin{array}{l}\text { If combined with a reader, full data } \\
\text { export over mobile phone network }\end{array}$ & $\begin{array}{l}\text { If combined with a reader, full data export over mobile phone network (data } \\
\text { transmission can automatically select between GPRS or more advanced networks } \\
\text { and GSM, based on available coverage). } \\
\text { GPRS should be able to use the internet FTP to transmit data: data transfer should } \\
\text { be initiated every } 6-12 \text { hours automatically by the reader; data can be exported } \\
\text { in a format compatible with HL-7 standards, where appropriate; instrument tracks } \\
\text { and transmits quality assurance data over time (eg, identify shifts or trends). }\end{array}$ \\
\hline $\begin{array}{l}\text { Target price per test (excluding the cost of a } \\
\text { device or reader)§ }\end{array}$ & $<$ US\$3 & $<$ US\$1.5 \\
\hline
\end{tabular}

*Should be guided by the knowledge of the local epidemics.

tBased on a sample size sufficient to achieve $\mathrm{Cls}$ of $\pm 5 \%$ around a point estimate of sensitivity and specificity.

$\$$ POCTs are only to provide a positive/negative result, other quantitative methods will be used for quantitation.

$\S$ It does not include the cost of device/reader in case the POCT is device based or/and requires a reader for the result.

FTP, File Transfer Protocol; GPRS, General Packet Radio Service; GPS, Global Positioning System; GSM, Global System for Mobile; MSM, men who have sex with men; POCT, point-

of-care testing; RPR, rapid plasma regain; SW, sex worker; TP, treponemal; TPP, target product profile; TPPA, Treponema pallidum particle agglutination.

the needs for such diagnostics in rural areas, a single-use, biodegradable or recyclable disposable diagnostic test was preferred, optionally equipped with a reader (small, portable, tabletop or handheld) that does not require external power supply. The IEG recommended the following clinical performance characteristics for ideal POCTs to detect genital gonococcal infection: sensitivity and specificity, 90\% minimal and 98\% optimal. The POCTs to detect genital chlamydial infection are expected to guarantee $>90 \%$ sensitivity (minimal) and 100\% (optimal). With regard to the specificity, the recommended values are $98 \%$ and $100 \%$ as minimal and optimal, respectively.

The operational characteristics include training requirements, less than $90 \mathrm{~min}$ minimally and no more than $30 \mathrm{~min}$ optimally. For the time to results, the minimal was specified as less than $60 \mathrm{~min}$ and the optimal as $30 \mathrm{~min}$ or less either for separate or combined NG and CT diagnostic platforms. If diagnostic platforms are equipped with a reader, it should include a Global Positioning System (GPS) module. The minimal acceptable target price per test was $<$ US $\$ 5$ (excluding the cost of a device or reader) and $<$ US\$1 optimally.

\section{T. vaginalis}

\section{Landscape}

Diagnosis of TV infection in women has traditionally been performed by microscopy of vaginal secretions, but this technique requires immediate evaluation of a wet preparation and is only about $50 \%$ sensitive when compared with culture or NAAT. ${ }^{32} 33$ Diagnosis of TV in men is typically from wet mount with microscopic visualisation of the parasites on slide preparations from urethral secretions. ${ }^{32}$ Modern nucleic acid-based testing for TV in either men or women is convenient, accurate and more sensitive than traditional methods. Like testing for CT and NG, there are a number of reliable laboratory-based molecular systems for TV testing.

In addition to these molecular tests, there is at least one rapid diagnostic test for detection of TV: the OSOM Trichomonas Test (Sekisui Diagnostics), an immunochromatographic capillary-flow enzyme immunoassay dipstick test detecting TV antigen that has shown to perform reasonably well when compared with a combined reference standard of wet mount and culture and/or PCR. ${ }^{34} 35$ GeneXpert (Cepheid) 


\begin{tabular}{|c|c|c|c|c|c|}
\hline Company & Cepheid & Atlas Genetics & Alere & Molbio/bigTec & Ustar \\
\hline Assay name & $\begin{array}{l}\text { GeneXpert } \\
\mathrm{CT}, \mathrm{CT} / \mathrm{NG}\end{array}$ & $\begin{array}{l}\text { Atlas io } \\
\mathrm{CT} ; \mathrm{CT} / \mathrm{NG} \text { (pipeline) }\end{array}$ & $\begin{array}{l}\text { Alere i } \\
\text { CT/NG (pipeline) }\end{array}$ & $\begin{array}{l}\text { Truelab PCR } \\
\text { CT, NG (pipeline) }\end{array}$ & $\begin{array}{l}\text { RT CPA HIV-1 Viral Load } \\
\text { CT (pipeline) }\end{array}$ \\
\hline Use setting & $\begin{array}{l}\text { Tabletop, not portable } \\
\text { Level 2-district hospital }\end{array}$ & $\begin{array}{l}\text { Tabletop; portable } \\
\text { Level 1—-health centre }\end{array}$ & $\begin{array}{l}\text { Tabletop; portable } \\
\text { Level 1—health centre }\end{array}$ & $\begin{array}{l}2 \text { instruments; not } \\
\text { portable; Level 2-district } \\
\text { hospital }\end{array}$ & Level 2-district hospital \\
\hline Steps & $\begin{array}{l}\sim 4 \text {; sample preparation } \\
\text { automated }\end{array}$ & $\begin{array}{l}\sim 4 \text {; automated sample } \\
\text { preparation on instrument }\end{array}$ & $\begin{array}{l}\sim 6 \text { simple steps; raw } \\
\text { sample added to device }\end{array}$ & Multiple pipetting steps & $\begin{array}{l}\sim 3-5 \text { steps from sample } \\
\text { to result }\end{array}$ \\
\hline Time to result & $\sim 90 \mathrm{~min}$ & $30 \mathrm{~min}$ & & $<60$ min & \\
\hline Training & Less than 0.5 day & $\begin{array}{l}\text { Less than } 1 \text { hour; no formal } \\
\text { training required; self- } \\
\text { explanatory user guide and } \\
\text { screens on instrument }\end{array}$ & Less than 0.5 day & Less than 0.5 day & Approximately 0.5 day \\
\hline Connectivity & $\begin{array}{l}\text { Yes; computer/internet required; } \\
\text { remote calibration }\end{array}$ & Yes; via middleware & $\begin{array}{l}\text { Yes; USB and Ethernet } \\
\text { outlets }\end{array}$ & Yes; wireless connectivity & $\begin{array}{l}\text { Will be used with Genie } \\
\text { device; TBD }\end{array}$ \\
\hline $\begin{array}{l}\text { Equipment cost (US\$); per } \\
\text { test cost }\end{array}$ & $\begin{array}{l}\sim \$ 17000 \text { (with } 4 \text { modules), but } \\
\text { could be higher; } \$ 16.20(\mathrm{CT} / \mathrm{NG} \text { ) }\end{array}$ & TBD & TBD & $\sim \$ 8000 ;$ TBD & $<\$ 5000 ;$ TBD \\
\hline
\end{tabular}

AC, alternating current; CT, Chlamydia trachomatis; DC, direct current; NG, Neisseria gonorrhoeae; POC, point of care; TBD, to be determined.

and Quidel (Quidel) have launched assays for TV, and Atlas Genetics has a TV assay in its development pipeline for 2017. These assays are described in table 8 .

\section{Target product profile}

All experts agreed that the main intended use of a POCT to detect TV is surveillance and case management in the sexually active population, including key populations (female SWs and STI clinic attendees), mainly in primary healthcare settings. Vaginal swabs as minimal and urine as an optimal option, including self-collected samples, were recommended by the IEG to perform qualitative testing. The results should be ideally obtained through no more than three (minimal) or one (optimal) non-labour-intensive operator steps and with minimal instructions for interpretation. The POCTs to detect TV are expected to ensure $85 \%$ sensitivity for samples collected by clinicians as minimal and $98 \%$ with both clinician and self-collected samples as optimal value. Recommended specificity ranged from minimal $99 \%$ to optimal $100 \%$.

If the diagnostic platform is equipped with a universal reader, it should include a GPS module, but only as an optimal characteristic of POCT. The training requirements, cost per test as well as time to result are the same as those recommended for POCTs to detect NG and CT. Such agreement among the assays should help align the introduction and testing procedures for all three infections within the context of case management in women.

\section{Human papillomavirus}

\section{Landscape}

In the USA, the Papanicolaou (Pap) test has been the gold standard for detecting cervical cancer in women over 30 years of age, mostly caused by HPV. However, the FDA recently recommended that the Cobas HPV Test (Roche) should be the first line of screening. HPV screening using either of these methods or using visual inspection with acetic acid (VIA) is difficult in resource-limited settings. The Cobas HPV Test, as other molecular-based tests must be performed in centralised laboratory facilities using sophisticated instrumentation. However, Qiagen has also introduced a molecular HPV assay, the careHPV Test, that is designed for use in low-resource settings. Performance of the assay has been good relative to either the Pap test or VIA. ${ }^{36} 37$

Of the diagnostic platforms discussed earlier in this report, GeneXpert (Cepheid) has a commercially available HPV assay (characteristics summarised in table 9). Several peer-reviewed, published studies of the assay found strong performance relative to laboratory-based reference standards in women referred for colposcopy. ${ }^{38-41}$ Cepheid also has an HPV assay in the pipeline for its new, smaller Omni platform, which is likely to be on the market in 2018. No other viable pipeline assays were identified.

\section{Target product profile}

The TPPs for HPV combined and mono-POCTs are presented in table 10 .

The IEG has also agreed to develop a stand-alone TPP for near-to-patient diagnostic platforms to detect HPV biomarkers (high-risk HPV (HPV16, 18, 31, 33, 35, 39, 45, 51, 52, 56, 58, 59 and 68)) oncoprotein or correlated, related biomarker (e.g., quantitative mRNA) for anal or cervical specimens. The TPP can be found on the website of WHO.

With regard to the TPP for POCTs targeting high-risk HPV $(16,18,31,33,35,39,45,51,52,56,58,59$ and 68), the expert group agreed that intended use should be screening in women between 30 and 64 years old and in HIV-positive women of all ages. The specimen should be provider-collected cervical or self-collected cervicovaginal (preferred because no need for speculum exam or clinic visit). The test should give a clear positive, negative or invalid result with minimal instructions for 
Table 6 TPP_combined/monogonococcal infection test

\begin{tabular}{|c|c|c|}
\hline Goal of test & \multicolumn{2}{|l|}{ To detect NG } \\
\hline Intended use and target patient* & \multicolumn{2}{|c|}{$\begin{array}{l}\text { Surveillance/case management: sexually active population, including key populations (eg, MSM, SW, STI clinic/service attendees) } \\
\text { Screening/regular testing: key populations }\end{array}$} \\
\hline Target use setting & \multicolumn{2}{|c|}{ Healthcare settings particularly at primary care level (level 1 ) or above } \\
\hline Results & \multicolumn{2}{|c|}{ Clear positive, negative or invalid result with minimal instructions for interpretation } \\
\hline Equipment & \multicolumn{2}{|c|}{$\begin{array}{l}\text { Single-use, biodegradable or recyclable disposable diagnostic test preferred, reader optional (small, portable, tabletop or handheld, no } \\
\text { electricity/power supply required) }\end{array}$} \\
\hline Target use(s) & \multicolumn{2}{|l|}{ Gonorrhoea testing patient with STI } \\
\hline Reference technology & \multicolumn{2}{|l|}{ Laboratory-based NAAT } \\
\hline Performance & Minimal & Optimal \\
\hline Clinical sensitivity ${ }^{\dagger}$ & $90 \%$ (genital) & $98 \%$ (genital) \\
\hline Clinical specificity & $90 \%$ (genital) & $>98 \%$ (genital) \\
\hline Quantitation & Not applicable & \\
\hline
\end{tabular}

Key minimal and optimal operational characteristics for gonococcal infection test

\begin{tabular}{|c|c|c|}
\hline & Minimal & Optimal \\
\hline Specimen§ & $\begin{array}{l}\text { Vaginal fluid in women and } \\
\text { urine in men }\end{array}$ & Urine in men and women, vaginal, rectal and pharyngeal \\
\hline $\begin{array}{l}\text { Steps performed by healthcare worker between } \\
\text { specimen preparation and result }\end{array}$ & $\begin{array}{l}\text { No more than three operator } \\
\text { steps that are not timed nor } \\
\text { labour intensive }\end{array}$ & One operator step (none of which has a timed interval), excluding waste disposal \\
\hline Training required & $<90 \min$ & $30 \mathrm{~min}$ \\
\hline Time to result & $=60 \mathrm{~min}$ & $=30 \mathrm{~min}$ \\
\hline Connectivity: device/reader & $\begin{array}{l}\text { If combined with a reader, reader } \\
\text { has integrated GPS module. }\end{array}$ & $\begin{array}{l}\text { If combined with a reader, internally integrated GPS/GPRS module and conformity with HL-7 } \\
\text { messaging standards }\end{array}$ \\
\hline Data export (for quality assurance): device/reader & $\begin{array}{l}\text { If combined with a reader, full } \\
\text { data export over mobile phone } \\
\text { network }\end{array}$ & $\begin{array}{l}\text { If combined with a reader, full data export over mobile phone network (data } \\
\text { transmission can automatically select between GPRS or more advanced networks and } \\
\text { GSM, based on available coverage). } \\
\text { GPRS should be able to use the internet FTP to transmit data: data transfer should } \\
\text { be initiated every } 6-12 \text { hours automatically by the reader; data can be exported in } \\
\text { a format compatible with HL-7 standards, where appropriate; instrument tracks and } \\
\text { transmits quality assurance data over time (eg, identify shifts or trends). }\end{array}$ \\
\hline $\begin{array}{l}\text { Target price per test (excluding the cost of a } \\
\text { device or reader) }\end{array}$ & $<U S \$ 5$ & $<U S \$ 1$ \\
\hline
\end{tabular}
device or reader)ף

*Should be guided by the knowledge of the local epidemics.

†Based on a sample size sufficient to achieve Cls of $\pm 5 \%$ around a point estimate of sensitivity and specificity.

\$POCTs are only to provide a positive/negative result, other quantitative methods will be used for quantitation.

$\S$ Sensitivity and specificity for rectal and pharyngeal swabs are not yet determined.

IIt does not include the cost of device/reader in case the POCT is device based or/and requires a reader for the result.

FTP, File Transfer Protocol; GPRS, General Packet Radio Service; GPS, Global Positioning System; MSM, men who have sex with men; NG, Neisseria gonorrhoeae; POCT, point-ofcare testing; SW, sex worker; TPP, target product profile.

interpretation and there should be no more than three non-labour-intensive steps minimally and one optimally. The required training should be maximum $90 \mathrm{~min}$ and optimally maximum $30 \mathrm{~min}$. Time to results should be onehour or less as minimal option and less than $30 \mathrm{~min}$ as optimal. The sensitivity has to be $85 \%$ minimally and $95 \%$ optimally, and for specificity no consensus was reached. If the diagnostic platform is equipped with a universal reader, it should include a GPS module and ideally be conform with HL-7 messaging standards. The cost per test has been set to maximum US $\$ 3$ and optimally not more than US $\$ 1.5$.

\section{Next-generation technologies}

In addition to the platforms described above that use conventional lateral flow and molecular techniques, some diagnostic platforms use what might be described as 'next-generation' technologies. The development of techniques that permit microscale fabrication and processing methods using silicon and the advances in plastics engineering can facilitate mass-produced, low-cost, ultraportable instrumentation with sophisticated sample and information processing capabilities that can be used effectively in diagnostics for use at the POC. ${ }^{42}$ Some of these are discussed below.

\section{Microscale and nanoscale detection technologies}

Demonstrable progress has been made in micro- and nanotechnologies for disease detection. These technologies can categorised as: optical and non-optical methods of detection. Non-optical detection methods, including electrical impedance sensing, are attractive for their simplicity; while optical sensing methods, once thought to be too costly, cumbersome and not sufficiently robust, are being aided by the latest advances in camera technologies, which put increasingly sophisticated imaging ability into smartphones. Cellphone technologies are already being used for diagnostic applications.

Optical methods of detection

Some of the most common optical detection methods are fluorescence, absorbance and chemiluminescence. ${ }^{43}$ Of these, fluorescence is most often used in diagnostics, including in 


\begin{tabular}{|c|c|c|}
\hline Goal of test & \multicolumn{2}{|l|}{ To detect CT } \\
\hline Intended use and target patient* & \multicolumn{2}{|c|}{$\begin{array}{l}\text { Surveillance/case management: sexually active population, including key populations (eg, MSM, SW, STI clinic/service attendees) } \\
\text { Screening/regular testing: under age of } 25 \text { years and key populations }\end{array}$} \\
\hline Target use setting & \multicolumn{2}{|c|}{ Healthcare settings particularly at primary care level (level 1) or above } \\
\hline Results & \multicolumn{2}{|c|}{ Clear positive, negative or invalid result with minimal instructions for interpretation } \\
\hline Equipment & \multicolumn{2}{|c|}{$\begin{array}{l}\text { Single-use, biodegradable or recyclable disposable diagnostic test preferred, reader optional (small, portable, tabletop or } \\
\text { handheld, no electricity/power supply required) }\end{array}$} \\
\hline Target use(s) & \multicolumn{2}{|l|}{ Testing patient with STI } \\
\hline Reference technology & \multicolumn{2}{|l|}{ Laboratory-based NAAT } \\
\hline Performance & Minimal & Optimal \\
\hline Clinical sensitivity & $>90 \%(L L>90 \%)$ (genital) & $100 \%$ (genital) \\
\hline Clinical specificity & 98\% (LL>95\%) (genital) & $100 \%$ (genital) \\
\hline Quantitation‡ & Not applicable & \\
\hline
\end{tabular}

\begin{tabular}{|c|c|c|}
\hline \multicolumn{3}{|c|}{ Key minimal and optimal operational characteristics for chlamydial infection test } \\
\hline & Minimal & Optimal \\
\hline Specimen§ & $\begin{array}{l}\text { First-catch urine }=2 \text { hours since last } \\
\text { void (all persons), healthcare worker- } \\
\text { collected vaginal swab }\end{array}$ & Any urine (all persons), self-collected vaginal swab \\
\hline Specimen preparation & $\begin{array}{l}\text { Minimal sample processing; no more } \\
\text { than one operator step }\end{array}$ & Integrated \\
\hline $\begin{array}{l}\text { Steps performed by healthcare worker between } \\
\text { specimen preparation and result }\end{array}$ & $\begin{array}{l}\text { No more than three operator steps } \\
\text { that are not timed nor labour } \\
\text { intensive }\end{array}$ & One operator step (none of which has a timed interval), excluding waste disposal \\
\hline Time to result & $=60 \mathrm{~min}$ & $=30 \mathrm{~min}$ \\
\hline Connectivity: device/reader & $\begin{array}{l}\text { If combined with a reader, reader has } \\
\text { integrated GPS module. }\end{array}$ & $\begin{array}{l}\text { If combined with a reader, internally integrated GPS/GPRS module and conformity with } \\
\mathrm{HL}-7 \text { messaging standards }\end{array}$ \\
\hline Data export (for quality assurance): device/reader & $\begin{array}{l}\text { If combined with a reader, full data } \\
\text { export over mobile phone network }\end{array}$ & $\begin{array}{l}\text { If combined with a reader, full data export over mobile phone network (data } \\
\text { transmission can automatically select between GPRS or more advanced networks } \\
\text { and GSM, based on available coverage). } \\
\text { GPRS should be able to use the internet FTP to transmit data: data transfer should } \\
\text { be initiated every } 6-12 \text { hours automatically by the reader; data can be exported } \\
\text { in a format compatible with HL-7 standards, where appropriate; instrument tracks } \\
\text { and transmits quality assurance data over time (eg, identify shifts or trends). }\end{array}$ \\
\hline $\begin{array}{l}\text { Target price per test (excluding the cost of a } \\
\text { device or reader) }\end{array}$ & $<U S \$ 5$ & $<$ US\$1 \\
\hline
\end{tabular}

\footnotetext{
*Should be guided by the knowledge of the local epidemics.

tBased on a sample size sufficient to achieve $\mathrm{Cls}$ of $\pm 5 \%$ around a point estimate of sensitivity and specificity.

$\$$ POCTs are only to provide a positive/negative result, other quantitative methods will be used for quantitation.

$\S$ Sensitivity and specificity for rectal and pharyngeal swabs are not yet determined.

IIt does not include the cost of device/reader in case the POCT is device based or/and requires a reader for the result.

CT, Chlamydia trachomatis; FTP, File Transfer Protocol; GPRS, General Packet Radio Service; GPS, Global Positioning System; GSM, Global System for Mobile; MSM, men who have sex with men; POCT, point-of-care testing; SW, sex worker; TPP, target product profile.
}

microscopy, flow cytometry and PCR. Microscale approaches often use fluorescence detection, frequently incorporating a laser or light-emitting diode (LED) for excitation of the tag. For example, fluorescence microscopy has been a standard method for detecting Mycobacterium (tuberculosis) in sputum samples. More recently, LED-based microscopy has increased access to microscopy in resource-limited settings. Fluorescence is also commonly used as an indicator in NAAT-based testing, either as a DNA intercalating dye or as part of a fluorophore-quencher system conjugated to probe DNA.

Chemiluminescence techniques are also being used in diagnostics for POC. Colorimetry has the advantage of providing a signal that is visible to the naked eye, which can eliminate the need for cameras in tests. Drawbacks include that instrument-based analysis of colorimetric signals is not as precise as other methods. An example of a microfluidics-based technology using colorimetry is the patterned paper technology from Diagnostics for All. The technology patterns channels and assay zones (or wells) of water-repellent materials into a piece of paper about the size of a postage stamp.

\section{Non-optical methods of detection}

In addition to optical methods of detection, there are also non-optical methods. Although electrical sensing techniques are frequently simpler and less expensive than optical methods, the downside is that they typically rely heavily on sample processing steps to remove background noise.

One electrical sensing method that has shown promise is impedance spectroscopy, typically using microfabricated electrodes, which measures electrical impedance of an aqueous solution as a function of alternating current frequency. Several applications in CD4 cell counting have been developed, ${ }^{445}$ and impedance-based cell counting approaches have also been used in the context of malaria diagnosis. ${ }^{434}$ Some commercial applications are already emerging. 
Table 8 POCTs_TV: summary of selected analytical and operational characteristics

\begin{tabular}{|c|c|c|c|}
\hline Company & Cepheid & Quidel & Atlas Genetics \\
\hline Assay name & GeneXpert & AmpliVue & Atlas io (pipeline) \\
\hline Use setting & $\begin{array}{l}\text { Tabletop; not portable } \\
\text { Level } 2\end{array}$ & $\begin{array}{l}\text { Tabletop; not portable } \\
\text { Level 2; need heat block; vortex }\end{array}$ & $\begin{array}{l}\text { Tabletop; portable } \\
\text { Level } 1\end{array}$ \\
\hline Specimen & $\begin{array}{l}\text { Female and male urine, endocervical swab/ } \\
\text { patient-collected vaginal swab }\end{array}$ & $\begin{array}{l}\text { Vaginal swabs from symptomatic and asymptomatic } \\
\text { women }\end{array}$ & $\begin{array}{l}\text { Self-collected and clinician-collected } \\
\text { vaginal swabs from symptomatic and } \\
\text { asymptomatic women, and urine from } \\
\text { men }\end{array}$ \\
\hline Steps & 4; sample preparation automated & Moderately complex; 12 steps; timed incubation & $\begin{array}{l}\sim 4 \text {; automated sample preparation on } \\
\text { instrument }\end{array}$ \\
\hline Time to result & $\sim 60 \mathrm{~min}$ & $45 \mathrm{~min}$ & $30 \mathrm{~min}$ \\
\hline Cold chain; reagent stability & Kit storage: $2^{\circ} \mathrm{C}-28^{\circ} \mathrm{C}$ & Cartridge/cassettes: $2^{\circ} \mathrm{C}-30^{\circ} \mathrm{C}$; buffers: $2^{\circ} \mathrm{C}-8^{\circ} \mathrm{C}$ & $\begin{array}{l}\text { Cartridges with reagents stable at } \\
2^{\circ} \mathrm{C}-25^{\circ} \mathrm{C}\end{array}$ \\
\hline Power & Mains power required; can use solar & Mains power required for heat block & Mains power required \\
\hline Training & Less than 0.5 day & Less than 0.5 day & $\begin{array}{l}\text { Less than } 1 \text { hour; no formal training } \\
\text { required; self-explanatory user guide and } \\
\text { screens on instrument }\end{array}$ \\
\hline Connectivity & $\begin{array}{l}\text { Yes; computer/internet required; remote } \\
\text { calibration }\end{array}$ & No & Yes; via middleware \\
\hline $\begin{array}{l}\text { Equipment cost (US\$); per } \\
\text { test }\end{array}$ & $\begin{array}{l}\sim \$ 17000 \text { (with } 4 \text { modules), but could be } \\
\text { higher; } \$ 19.00\end{array}$ & TBD & TBD \\
\hline
\end{tabular}

Level 1 =primary healthcare centre. Level 2 =district hospital.

POCT, point-of-care testing; TBD, to be determined; TV, Trichomonas vaginalis.

\section{Other promising technological developments}

Other promising technologies include electrochemical approaches, although they are limited to enzymes and reagents that are capable of producing an electrochemical signal. For example, Aalto Bio Reagents is developing a unique lab-on-achip technology that uses an electrochemical immunoassay technology with an immune-electrode detector to produce a sample-to-answer result from a patient specimen in less than $15 \mathrm{~min}$.

Finally, other non-optical approaches may detect mass or mechanical forces. The potential downside is that mechanical sensors may not be robust enough for handheld diagnostic test platforms. In addition, thanks to improved microfabrication techniques, innovative approaches are being made possible by increasingly miniaturised measurement techniques that have the potential to be used in diagnostics. For example, mass spectrometry has already been miniaturised and coupled with microfluidic devices. ${ }^{45}$

\begin{tabular}{ll}
\hline $\begin{array}{l}\text { Table } 9 \\
\text { HPV assay }\end{array}$ Analytical and operational characteristics of the Cepheid \\
\hline $\begin{array}{l}\text { Company } \\
\text { Use setting }\end{array}$ & $\begin{array}{l}\text { Cepheid } \\
\text { Tabletop; not portable } \\
\text { Level } 2\end{array}$ \\
\hline $\begin{array}{l}\text { Specimen } \\
\text { Training }\end{array}$ & Female endocervical swab \\
\hline Time to result & Less than 0.5 day \\
\hline Power & Mains power required \\
Connectivity & Yes; computer/internet required; remote calibration \\
\hline Equipment cost (US\$); per test & $\sim$ US\$17000 (with 4 modules), but could be higher; \\
& $\$ 16.70$ \\
\hline
\end{tabular}

Level $2=$ district hospital.

HPV, human papillomavirus; TBD, to be determined.

In summary, some next-generation technologies appear to have promising applications for diagnostics at POC, but to date few of them have been commercialised. ${ }^{\text {iii }}$ In addition, there is a long and arduous road from demonstrating the use of these technologies either for enrichment of a biological sample or the sensitive detection of an analyte to a combined sample-in, result-out diagnostic platform. The integration of these techniques is a big challenge, but only when all components of a test have been combined into a self-contained device that can be used at POC can new technologies realise their full promise for improving global health.

\section{DISCUSSION AND CONCLUSIONS}

Because of the generally good performance of syphilis POCTs, there is arguably no need for additional mono tests. However, there are several important needs for new syphilis dual tests, preferably in the form of POCTs, in resource-limited settings. One of these is for a combination TP/non-TP test that can be used to diagnose syphilis, and preferably differentiate active syphilis at the POC where traditional laboratory-based testing may not be available. Another need is for HIV/syphilis dual as well as HIV/syphilis/hepatitis B virus (HBV) tests. The latter is needed to support the current efforts for the triple elimination of vertical transmission of $\mathrm{HBV}$, syphilis and $\mathrm{HIV},{ }^{14}$ requiring strong screening components for all three infections.

With respect to other STIs, there are reasonably robust molecular platforms for which assays for CT, NG, TV and HPV are currently being developed. One platform, from Cepheid, already provides assays for CT, NG, CT/NG, TV and HPV. Other platforms designed for use at or near the point of patient care will have similar capabilities. However, a number of these platforms are more appropriate for use at the district hospital level or above in resource-limited settings. This offers some degree of test decentralisation and should help increasing access to testing, but in order to truly expand access and reach more patients, it will be necessary

\footnotetext{
iii See Sharma et al for a list of FDA-approved microfluidic-based tests for use at the point of care.(63) The list includes platforms from Alere, BD, Abbott and Roche.
} 


\begin{tabular}{|c|c|c|}
\hline Goal of test & \multicolumn{2}{|c|}{$\begin{array}{l}\text { To detect clinically relevant }(=1.0 \mathrm{pg} / \mathrm{mL}) \text { high-risk HPV (HPV 16, 18, 31, 33, 35, 39, 45, 51, 52, 56, 58, } 59 \text { and 68), HPV DNA } \\
\text { or RNA; correlated with CIN3+ }\end{array}$} \\
\hline Intended use and target patient* & \multicolumn{2}{|c|}{ Screening: women aged 30-64 years or HIV-positive women at any age } \\
\hline Target use setting & \multicolumn{2}{|c|}{$\begin{array}{l}\text { To detect clinically relevant }(=1.0 \mathrm{pg} / \mathrm{mL} \text { ) high-risk HPV (HPV 16, 18, 31, 33, 35, 39, 45, 51, 52, 56, } 58,59 \text { and 68), HPV DNA } \\
\text { or RNA; correlated with CIN3+ }\end{array}$} \\
\hline Results & \multicolumn{2}{|c|}{ Clear positive, negative or invalid result with minimal instructions for interpretation } \\
\hline \multicolumn{3}{|l|}{ Target use(s) } \\
\hline Reference technology & \multicolumn{2}{|l|}{ Laboratory-based NAAT } \\
\hline Performance & Minimal & Optimal \\
\hline Clinical sensitivity $\dagger$ & $85 \%$ & $95 \%$ \\
\hline Clinical specificity & $\ddagger$ & \\
\hline
\end{tabular}

Key minimal and optimal operational characteristics for HPV DNA or RNA test

\begin{tabular}{|c|c|c|}
\hline & Minimal & Optimal \\
\hline Specimen & $\begin{array}{l}\text { Provider-collected cervical specimen and self- } \\
\text { collected cervicovaginal specimen (preferred } \\
\text { because no need for speculum exam or clinic visit) }\end{array}$ & $\begin{array}{l}\text { Provider-collected cervical specimen and self-collected cervicovaginal } \\
\text { specimen (preferred because no need for speculum exam or clinic visit) }\end{array}$ \\
\hline $\begin{array}{l}\text { Steps performed by healthcare worker between } \\
\text { specimen preparation and result }\end{array}$ & $\begin{array}{l}\text { No more than three operator steps that are not } \\
\text { timed nor labour intensive }\end{array}$ & $\begin{array}{l}\text { Maximum one operator step (none of which has a timed interval), } \\
\text { excluding waste disposal }\end{array}$ \\
\hline Training required & $<90 \min$ & $30 \mathrm{~min}$ \\
\hline Time to result & $=60 \mathrm{~min}$ & $=30 \mathrm{~min}$ \\
\hline Regulatory requirements & Compliance with appropriate ISO standard & \\
\hline Connectivity: device/reader & $\begin{array}{l}\text { If combined with a reader, reader has integrated } \\
\text { GPS module. }\end{array}$ & $\begin{array}{l}\text { If combined with a reader, internally integrated GPS/GPRS module and } \\
\text { conformity with HL-7 messaging standards }\end{array}$ \\
\hline Data export (for quality assurance): device/reader & $\begin{array}{l}\text { If combined with a reader, full data export over } \\
\text { mobile phone network }\end{array}$ & $\begin{array}{l}\text { If combined with a reader, full data export over mobile phone } \\
\text { network (data transmission can automatically select between GPRS } \\
\text { or more advanced networks and GSM, based on available coverage). } \\
\text { GPRS should be able to use the internet FTP to transmit data: data } \\
\text { transfer should be initiated every 6-12 hours automatically by the } \\
\text { reader; data can be exported in a format compatible with HL-7 } \\
\text { standards, where appropriate; instrument tracks and transmits } \\
\text { quality assurance data over time (eg, identify shifts or trends). }\end{array}$ \\
\hline Target price per test (excluding the cost of a & $<$ US\$3 & $<$ US\$1.5 \\
\hline
\end{tabular}

device or reader) $\uparrow$

Link to full target product profile-combined/mono-HPV DNA or RNA test

*Should be guided by the knowledge of the local epidemics.

tBased on a sample size sufficient to achieve Cls of $\pm 5 \%$ around a point estimate of sensitivity and specificity.

$\ddagger$ Values are currently under revision.

§OCTs are only to provide a positive/negative result, other quantitative methods will be used for quantitation.

ףlt does not include the cost of device/reader in case the POCT is device based or/and requires a reader for the result.

FTP, File Transfer Protocol; GPRS, General Packet Radio Service; GPS, Global Positioning System; GSM, Global System for Mobile; HPV, human papillomavirus; ISO, International

Organization for Standardization; POCT, point-of-care testing; TPP, target product profile.

to locate test platforms at the primary healthcare level where laboratories are often quite basic.

Despite the current pipeline for POC STI platforms, there is still a need to develop tests that can be effectively used at primary healthcare centres in resource-constrained settings with which test results can be provided to patients to inform clinical care at a single visit. The impact of these increasingly sophisticated diagnostic technologies will be limited unless they can successfully accommodate the weaknesses in healthcare systems in resource-constrained settings, which often affect the successful delivery of diagnostics in-country. These include: shortages of human resources and lack of training for staff; supply chain challenges; lack of diagnostic equipment and equipment breakdowns; and a lack of robust quality assurance and quality control systems.

These weaknesses suggest the need for training of test operators and service and maintenance contracts for diagnostics, and that the following operational specifications for POC diagnostic assays/platforms should be prioritised: (1) ease of use; (2) training; (3) high tolerance to difficult environmental conditions and high shelf life; (4) self-contained quality control; (5) data capture/connectivity/data export; (6) biosafety; and (7) waste disposal. In addition, other specifications must also be emphasised. These include cost, sample capacity/throughput and time to result.

These factors, along with required technical performance, must be considered and prioritised by developers of diagnostics intended for use at POC in resource-limited settings. The TPPs for STI POCTs aim to guide future development. The targets of clinical sensitivity and specificity of POCTs across all TPPs address the needs for differentiating between screening, case finding and STI surveillance. This should permit an appropriate trade-off throughout all stages of the POCT pipeline-development, validation and implementation. The targets of performance and other parameters range from minimal to optimal, 
giving the necessary space for manoeuvring between implementation of existing tests (minimal) and development of new tests (optimal). It is only when the required technical specifications and preferred operational specifications are integrated into a single platform that new tests for STIs will be well positioned to achieve the desired level of uptake and impact on global health.

The absence of representatives from manufacturers in the consultation process could be considered a limitation, particularly with regard to the operational characteristics of desired POCTs. This was counterbalanced by the large spectrum of expertise in different fields and from various geographical areas in our consultative group. As the field of POCTs is both constantly evolving and dispersed, it is possible that some promising technologies have been unintentionally omitted.

Notwithstanding these limitations, the landscape analysis and TPPs inform both the development of new diagnostic platforms and support the validation and implementation of the existing diagnostic tests positioned by the manufacturers as POC or near-to-patient tests. Regular updates of TPPs and reviews of the diagnostic landscape for targeted STIs should continue to be integral parts of this process. Guiding developers, producers, researchers and implementers on the critical parameters of the desired POCTs and including industry, researchers, clinicians, policymakers, donors and affected populations will help reduce the gaps between the current and future diagnostic technologies and public health needs.

\section{Key messages}

- The target product profiles and landscape analysis contribute to the global efforts to accelerate access to reliable and affordable point-of-care testing (POCT) through standardisation of requirements of diagnostic assays.

- Both documents are dynamic and should be regularly updated using a multidisciplinary and multistakeholder approach, ensuring buy-in and common understanding of the main outcomes.

- Further engagement of representatives of both the field and manufacturers is critical for setting up realistic and achievable goals for POCTs of interest.

\section{Handling editor Jackie A Cassel}

Acknowledgements The participants of the meetings were: Moazzam Ali (WHO, Geneva, Switzerland), David Anderson (Burnet Institute, Melbourne, Australia), Manju Bala (VMMC \& Safdarjung Hospital, New Dehli, India), Ron Ballard, Karel Blondeel (WHO, Geneva, Switzerland), Viviane Bremer (ECDC, Berlin, Germany), Nathalie Broutet (WHO, Geneva, Switzerland), Jordi Casabona (CEEISCAT, Barcelona, Spain), Philip Castle (Global Coalition against Cervical Cancer, Arlington, USA), Fatim Cham-Jallow (Makere University, Kampala, Uganda), Xiang-Sheng Chen (Chinese Academy of Medical Sciences, Nanjing, China), Joanna Cordero (WHO, Geneva, Switzerland), Antonina Crucitti (Institute of Tropical Medicine, Antwerp, Belgium), Carolyn Deal (NIH, Maryland, USA), David Dolinger (FIND, Geneva, Switzerland), Yetunde Fakile (CDC, Atlanta, USA), Tim Farley (Sigma3 Services, Nyon, Switzerland), Mario Festin (WHO, Geneva, Switzerland), Miriam Franchini (Brazilian National STI AIDS and Hepatitis Program, Brasilia, Brazil), Sebastian Fuller (Public Health England, London, UK), Patricia Garcia (Cayetano University, Lima, Peru), Charlotte Gaydos (Johns Hopkins University, Baltimore, USA), Sami Gottlieb (WHO, Geneva, Switzerland), Vadum Govorun (Institute of Physico-Chemical Medicine, Moscow, Russian Federation), Catherine Ison (Public Health England, London, UK), Rita Kabra (WHO, Geneva, Switzerland), Mary Kamb (CDC, Atlanta, USA), Kevin Karem (CDC, Atlanta, USA), Maura Laverty (WHO, Geneva, Switzerland), James Kiarie (WHO, Geneva, Switzerland), David Lewis (National Institute for Communicable Diseases, Johannesburg, South Africa), David Mabey (London School of Hygiene and Tropical Medicine, London, UK), Jessica Markby (WHO, Geneva, Switzerland), Natalie Maurer (WHO, Geneva, Switzerland), Oleg Medvedev (Lomonosov Moscow State University, Moscow, Russian Federation), Mario Merialdi (former WHO, Geneva, Switzerland), Robyn Meurant (WHO, Geneva, Switzerland), Maurine Murthagh
(International Diagnostics Centre, Woodside, USA), Francis Ndowa (former WHO, Geneva, Switzerland), Lori Newman (WHO, Geneva, Switzerland), Rosanna Peeling (London School of Hygiene and Tropical Medicine, London, UK), Maria PerezGonzales (WHO, Geneva, Switzerland), Tariq Sadiq (University London, UK), Anita Sands (WHO, Geneva, Switzerland), Adele Schwartz Benzaken (National AIDS Programme, Brazil), Mark Shepard (Finders University, Adelaide, Australia), Samuel Sia (Colombia University, New York, USA), Marleen Temmerman (former WHO, Geneva, Switzerland), Igor Toskin (WHO, Geneva, Switzerland), Thierry Troussier (UNESCO Chair Sexual Health and Human Rights, Paris, France), Ozge Tuncalp Mingard (WHO, Geneva, Switzerland), Magnus Unemo (Orebro University Hospital, Sweden), Shery Vnaderpoel (WHO, Geneva, Switzerland) Brenda Waning (UNITAID, Geneva, Switzerland), Anna Whalen (FIND, Geneva, Switzerland), Teodora Wi (WHO, Geneva, Switzerland).

Contributors IT and MM designed the concept and methodology; IT, MM, KB, RWP and JC conducted the analysis and synthesis of the results. All authors contributed to the finalisation of the manuscript.

Disclaimer The authors are staff members of the World Health Organization. The authors alone are responsible for the views expressed in this publication and they do not necessarily represent the views, decisions or policies of the World Health Organization.

\section{Competing interests None declared.}

Provenance and peer review Commissioned; externally peer reviewed.

(c) World Health Organization 2017. Licensee BMJ Publishing Group Limited. This is an open access article distributed under the terms of the Creative Commons Attribution IGO License (https://creativecommons.org/licenses/by/3.0/igo), which permits use, distribution, and reproduction for non-commercial purposes in any medium, provided the original work is properly cited. In any reproduction of this article there should not be any suggestion that WHO or this article endorse any specific organization or products. The use of the WHO logo is not permitted. This notice should be preserved along with the article's original URL.

\section{REFERENCES}

1 Newman L, Rowley J, Vander Hoorn S, et al. Global estimates of the prevalence and incidence of four curable sexually transmitted infections in 2012 based on systematic review and global reporting. PLoS One 2015;10:e0143304.

2 World Health Organization. Sexually transmitted infections - Fact Sheet 110. Geneva: WHO, 2013. http://www.who.int/mediacentre/factsheets/fs110/en/ (accessed 17 Sep 2017).

3 Peeling RW. Applying new technologies for diagnosing sexually transmitted infections in resource-poor settings. Sex Transm Infect 2011;87 Suppl 2:ii28-ii30.

4 World Health Organization. The use of rapid syphilis tests. Geneva:WHO/TDR, 2006 http://apps.who.int/iris/bitstream/10665/43590/1/TDR_SDI_06.1_eng.pdf (accessed 17 Sep 2017)

5 World Health Organization. Global HIVIAIDS response: epidemic update and health sector progress towards universal access. Geneva: WHO, 2011. http://www.who.int/ hiv/pub/progress_report2011/en/ (accessed 7 Jul 2017)

6 World Health Organization. Laboratory diagnosis of sexually transmitted infections, including human immunodeficiency virus. Geneva: WHO, 2013. http://who.int/ reproductivehealth/publications/rtis/9789241505840/en/ (accessed 7 Jul 2017).

7 World Health Organization. WHO Global Strategy for the prevention and control of sexually transmitted infections: 2006-2015. Geneva: WHO, 2007. http://www. who.int/reproductivehealth/publications/rtis/9789241563475/en/ (accessed $7 \mathrm{Ju}$ 2017).

8 Wedderburn CJ, Murtagh M, Toskin I, et al. Using electronic readers to monitor progress toward elimination of mother-to-child transmission of HIV and syphilis: An opinion piece. Int J Gynaecol Obstet 2015;130 Suppl 1:(6):S81-S83.

9 World Health Organization. Global Health Sector Strategy on Sexually Transmitted Infections, 2016-2021. Geneva:WHO, 2016. http://www.who.int/reproductivehealth/ publications/rtis/ghss-stis/en/ (accessed 7 Jul 2017)

10 Mabey D, Peeling RW, Ballard R, et al. Prospective, multi-centre clinic-based evaluation of four rapid diagnostic tests for syphilis. Sex Transm Infect 2006;82 Suppl 5:v13-v16.

11 Campos PE, Buffardi AL, Chiappe M, et al. Utility of the Determine Syphilis TP rapid test in commercial sex venues in Peru. Sex Transm Infect 2006;82 Suppl 5:v22-v25.

12 Yin YP, Peeling RW, Chen XS, et al. Clinic-based evaluation of Clearview Chlamydia MF for detection of Chlamydia trachomatis in vaginal and cervical specimens from women at high risk in China. Sex Transm Infect 2006:82 Suppl 5:v33-v37.

13 Benzaken AS, Galban EG, Antunes W, et al. Diagnosis of gonococcal infection in high risk women using a rapid test. Sex Transm Infect 2006;82 Suppl 5:v26-v28.

14 Hsieh YH, Gaydos CA, Hogan MT, et al. Perceptions on point-of-care tests for sexually transmitted infections - comparison between frontline clinicians and professionals in industry. Point Care 2012;11:126-9.

15 Murtagh M. The point-of-care diagnostic landscape for sexually transmitted infections(STIS). http://who.int/reproductivehealth/topics/rtis/pocts/en/ (accessed 17 Sep 2017) 
16 UNITAID. Dual elimination of mother-to-child transmission of HIV and congenital syphilis: diagnostic technology landscape. Geneva: UNITAID, 2014. http://www. unitaid.eu/images/marketdynamics/publications/UNITAID-HIV_Congenital_Syphilis_ Diagnostic_Landscape.pdf (accessed 17 Sep 2017).

17 Jafari Y, Peeling RW, Shivkumar S, et al. Are Treponema pallidum specific rapid and point-of-care tests for syphilis accurate enough for screening in resource limited settings? Evidence from a meta-analysis. PLoS One 2013;8:e54695.

18 Causer LM, Kaldor JM, Fairley CK, et al. A laboratory-based evaluation of four rapid point-of-care tests for syphilis. PLoS One 2014;9:e91504.

19 Nakku-Joloba E, Kiragga A, Mbazira JK, et al. Clinical evaluation of 2 point-of-care lateral flow tests for the diagnosis of syphilis. Sex Transm Dis 2016;43:623-5.

20 Castro AR, Esfandiari J, Kumar $\mathrm{S}$, et al. Novel point-of-care test for simultaneous detection of nontreponemal and treponemal antibodies in patients with syphilis. J Clin Microbiol 2010;48:4615-9.

21 Yin YP, Chen XS, Wei WH, et al. A dual point-of-care test shows good performance in simultaneously detecting nontreponemal and treponemal antibodies in patients with syphilis: a multisite evaluation study in China. Clin Infect Dis 2013;56:659-65.

22 Causer LM, Kaldor JM, Conway DP, et al. An evaluation of a novel dual treponemal/ nontreponemal point-of-care test for syphilis as a tool to distinguish active from past treated infection. Clin Infect Dis 2015;61:184-91.

23 Gaydos C, Hardick J. Point of care diagnostics for sexually transmitted infections: perspectives and advances. Expert Rev Anti Infect Ther 2014;12:657-72.

24 Huppert J, Hesse E, Gaydos CA. What is the point? how point-of-care sexually transmitted infection tests can impact infected patients. Point Care 2010;9:36-46.

25 Nuñez-Forero L, Moyano-Ariza L, Gaitán-Duarte H, et al. Diagnostic accuracy of rapid tests for sexually transmitted infections in symptomatic women. Sex Transm Infect 2016;92:24-8.

26 Guy RJ, Causer LM, Klausner JD, et al. A review of studies evaluating the performance and operational characteristics of point-of-care tests for the diagnosis of genital gonococcal infections. Sex Transm Infect In press.

27 Kelly H, Colthart C, Pai N, et al. Systematic reviews of point-of-care tests for the diagnosis of urogenital Chlamydia trachomatis infections. Sex Transm Infect In press.

28 Peeling RW, Holmes KK, Mabey D, et al. Rapid tests for sexually transmitted infections (STIs): the way forward. Sex Transm Infect 2006;82 Suppl 5:v1-v6.

29 Xpert CT/NG White Paper. http://www.cepheid.com/en/cepheid-solutionsuk/clinicalivd-tests/sexual-health/xpert-ct-ng (accessed 17 Sep 2017).

30 Gaydos CA, Van Der Pol B, Jett-Goheen M, et al. Performance of the Cepheid CT/ NG Xpert Rapid PCR Test for Detection of Chlamydia trachomatis and Neisseria gonorrhoeae. J Clin Microbiol 2013;51:1666-72

31 Tabrizi SN, Unemo M, Golparian D, et al. Analytical evaluation of GeneXpert CT/ $N G$, the first genetic point-of-care assay for simultaneous detection of neisseria gonorrhoeae and chlamydia trachomatis. J Clin Microbiol 2013;51:1945-7.

32 Madico G, Quinn TC, Rompalo A, et al. Diagnosis of trichomonas vaginalis infection by PCR using vaginal swab samples. J Clin Microbiol 1998;36:3205-10.
33 Wendel KA, Erbelding EJ, Gaydos CA, et al. Trichomonas vaginalis polymerase chain reaction compared with standard diagnostic and therapeutic protocols for detection and treatment of vaginal trichomoniasis. Clin Infect Dis 2002;35:576-80.

34 Huppert JS, Mortensen JE, Reed JL, et al. Rapid antigen testing compares favorably with transcription-mediated amplification assay for the detection of Trichomonas vaginalis in young women. Clin Infect Dis 2007;45:194-8.

35 Gaydos CA, Klausner JD, Pai NP, et al. Rapid and point-of-care tests for the diagnosis of Trichomonas vaginalis in women and men. Sex Transm Infect 2017:sextrans-2016-053063.

36 Jeronimo J, Bansil P, Lim J, et al. A multicountry evaluation of care HPV testing, visual inspection with acetic acid, and papanicolaou testing for the detection of cervical cancer. Int J Gynecol Cancer 2014;24:576-85.

37 Labani S, Asthana S, Sodhani P, et al. CareHPV cervical cancer screening demonstration in a rural population of north India. Eur J Obstet Gynecol Reprod Biol 2014:176:75-9.

38 Einstein MH, Smith KM, Davis TE, et al. Clinical evaluation of the cartridge-based GeneXpert human papillomavirus assay in women referred for colposcopy. J Clin Microbiol 2014;52:2089-95.

39 Castle PE, Smith KM, Davis TE, et al. Reliability of the Xpert HPV assay to detect highrisk human papillomavirus DNA in a colposcopy referral population. Am J Clin Pathol 2015;143:126-33.

40 Cuzick J, Cuschieri K, Denton K, et al. Performance of the Xpert HPV assay in women attending for cervical screening. Papillomavirus Res 2015;1:32-7

41 Cuschieri K, Geraets D, Cuzick J, et al. Performance of a cartridge-based assay for detection of clinically significant Human Papillomavirus (HPV) Infection: lessons from VALGENT (Validation of HPV Genotyping Tests). J Clin Microbiol 2016;54:2337-42.

42 Damhorst GL, Murtagh M, Rodriguez WR, et al. Microfluidics and nanotechnology for detection of global infectious diseases. Proc IEEE Inst Electr Electron Eng 2015;103:150-60.

43 Kuswandi B, Nuriman, Huskens J, et al. Optical sensing systems for microfluidic devices: a review. Anal Chim Acta 2007;601:141-55.

44 Watkins NN, Hassan U, Damhorst G, et al. Microfluidic CD4+ and CD8+ T lymphocyte counters for point-of-care HIV diagnostics using whole blood. Sci Trans/ Med 2013;5:214ra170.

45 Cheng $X$, Liu YS, Irimia D, et al. Cell detection and counting through cell lysate impedance spectroscopy in microfluidic devices. Lab Chip 2007;7:746-55.

46 Laboratory detection of trichomonas. Silver Spring: APHL 2013 http://www.aph. org/AboutAPHL/publications/Documents/ID_2013August_Advances-in-LaboratoryDetection-of-Trichomonas-vaginalis.pdf (accessed 5 Sep 2017).

47 Du E, Ha S, Diez-Silva M, et al. Electric impedance microflow cytometry for characterization of cell disease states. Lab Chip 2013;13:3903-9.

48 Ha S, Diez-Silva M, Du S, et al. Microfluidic electric impedance spectroscopy for malaria diagnosis. Miniaturized Syst Chem Life Sci 2012:1960-2.

49 Gao D, Liu H, Jiang Y, et al. Recent advances in microfluidics combined with mass spectrometry: technologies and applications. Lab Chip 2013;13:3309-22. 